\title{
Effect of ambient temperature on outpatient admission for osteoarthritis and rheumatoid arthritis in a subtropical Chinese city
}

\section{Desheng Zhao}

Department of medical administration, The First Affiliated Hospital of USTC, Division of Life Sciences and Medicine, University of Science and Technology of China, Hefei 230001, Anhui

Jian Cheng

School of Public Health and Social Work \& Institute of Health and Biomedical Innovation, Queensland University of Technology, Australia

\section{Ping Bao}

Department of medical administration, The First Affiliated Hospital of USTC, Division of Life Sciences and Medicine, University of Science and Technology of China, Hefei 230001, Anhui

\section{Yanwu Zhang}

Nursing Department, The First Affiliated Hospital of USTC, Division of Life Sciences and Medicine, University of Science and Technology of China, Hefei 230001, Anhui

\section{Fengjuan Liang}

Department of medical administration, The First Affiliated Hospital of USTC, Division of Life Sciences and Medicine, University of Science and Technology of China, Hefei 230001, Anhui

\section{Hao Wang}

Information Center, The First Affiliated Hospital of USTC, Division of Life Sciences and Medicine, University of Science and Technology of China, Hefei 230001, Anhui

\section{Xu Wang}

Anhui Provincial Children's Hospital, Hefei, Anhui Province, China

\section{Shiyuan Fang ( $\square$ fangshiyuan2008@126.com )}

Department of medical administration, The First Affiliated Hospital of USTC, Division of Life Sciences and Medicine, University of Science and Technology of China

\section{Hong Su ( $\nabla$ suhong5151@sina.com )}

Department of Epidemiology and Health Statistics, School of Public Health, Anhui Medical University, Hefei, Anhui 230032, China

\section{Research article}

Keywords: Temperature, osteoarthritis, rheumatoid arthritis, admission 
Posted Date: July 20th, 2020

DOl: https://doi.org/10.21203/rs.3.rs-34830/v1

License: (c) (i) This work is licensed under a Creative Commons Attribution 4.0 International License. Read Full License

Version of Record: A version of this preprint was published at BMC Public Health on January 25th, 2022. See the published version at https://doi.org/10.1186/s12889-021-11994-0. 


\section{Abstract \\ Background}

Current findings on the impact of weather conditions on osteoarthritis (OA) and rheumatoid arthritis (RA) are sparse and not conclusive. This study aimed to investigate the relationship between temperature change and OA/RA admission.

\section{Methods}

Daily OA/RA admission and meteorological data from 1 January 2014 to 31 December 2017 in Hefei, China, were collected. We quantified the relationship between ambient temperature and OA/RA admission using a distributed lag nonlinear model (DLNM). The effect modifications by gender and age were also examined.

\section{Results}

Sudden temperature decrease was significantly associated with RA admission (25th percentile of temperature versus 50th percentile of temperature), with the acute and largest effect at current days lag (RR: $1.063,95 \% \mathrm{Cl}: 1.010-1.118$ ). However, no association between temperature and OA admission was observed. When conducting subgroup analyses by individual characteristics, we found that females and patients aged 41-65 years were more vulnerable to temperature decrease than males, patients aged 040 and $\geqq 66$ years, respectively.

\section{Conclusions}

This study suggested that sudden temperature decrease was a risk factor for increase RA admission. Females and patients aged 41-65 years were particularly vulnerable to the effect of temperature decrease.

\section{Background}

Osteoarthritis (OA) and rheumatoid arthritis (RA) are the two most common joint disorders [1]. According to the Global Burden of Disease (GBD) study in 2018, the worldwide prevalence of OA was $41.1 \%$ ond the number of patients reached 303.1 million by the year 2017. Meanwhile, RA affect about 19.9 million people, which account for $2.7 \%$ of the total population. Between 2007 and 2017, the number of all-age years lived with disability (YLDs) attributed to OA/RA increased by $33.5 \%$ and $31.4 \%$, respectively [2]. Given the considerable disease burden of OA/ RA, the comprehensive understanding of the risk factors for OA/RA is important for disease prevention and control. Besides genetic, immune and infectious factors, the assumption that weather influences signs and symptoms of OA and RA is widespread. 
Previous studies have explored the relationship of joint pain in OA/RA with weather conditions [3-13], such as temperature and humidity, but with conflicting results [13]. For example, some studies reported that temperature decrease might influence the experience of joint pain in patients with OA/RA [3-5]. However, no association was observed in the findings of other studies $[8,11]$. This difference may be due to a number of factors, including the diversity weather pattern in different regions, demographic characteristics and methodological limitations. In most previous studies, little attention was paid to the lagged effects of temperature change on OA/ RA. Therefore, more efforts are needed to provide evidence on the risk of experiencing pain onset with changes in temperature, in persons with OA/RA. In recent years, time-series analysis has been increasingly used to assess the impacts of climate change on human health. As one of the most commonly used statistical approach in time-series analysis, DLNM model has the merit of investigating exposure-lag-response relationship between environmental variables and health outcomes, temperature and various diseases for example [14].

The aim of this study was to employ DLNM to examine the relationship between temperature change and outpatient admission for OA and RA in Hefei, and explore whether age or gender modified this relationship.

\section{Methods}

\section{Study area}

This study was conducted in Hefei, which is the capital and largest city of Anhui province in Eastern China with a population of 8.09 million inhabitants (from 2018 census data). Hefei has a humid subtropical climate with mean temperature was $16.8^{\circ} \mathrm{C}$.

\section{Arthritis data}

Daily counts of outpatient admission for OA/RA during 2014-2017 were obtained from The First Affiliated Hospital of University of Science and Technology of China (Anhui Provincial Hospital). The patient data included date of outpatient admission, age, gender, residential address. Diagnosis of OA (ICD-10: M13.9) and RA (ICD-10: M06.9) was coded according to the International Classification of Disease, 10th Revision (ICD-10). Ethical approval was obtained from the Ethics Committee of Anhui Provincial Hospital prior to data collection.

\section{Weather and air pollutants data}

Meteorological data on daily mean temperature, relative humidity, rainfall, barometric pressure and wind velocity during the same period were obtained from Hefei Bureau of Meteorology. Air pollution data including average daily level of sulfur dioxide $\left(\mathrm{SO}_{2}\right)$, nitrogen dioxide $\left(\mathrm{NO}_{2}\right)$, carbon monoxide (CO), ozone $\left(\mathrm{O}_{3}\right)$, particulate matter of less than $10 \mu \mathrm{m}$ and $2.5 \mu \mathrm{m}\left(\mathrm{PM}_{10}\right.$ and $\left.\mathrm{PM}_{2.5}\right)$ were collected from the Environmental Protection Bureau in Hefei. Daily 24-h mean concentrations of $\mathrm{SO}_{2}, \mathrm{NO}_{2}, \mathrm{CO}, \mathrm{PM}_{10}$ and 
$\mathrm{PM}_{2.5}$, and daily maximum 8-hour mean concentrations of $\mathrm{O}_{3}$ were calculated. Consistent with previous study [15], we chose the 50th percentile of temperature $\left(P 50,17.8^{\circ} \mathrm{C}\right)$ as the reference in analyses.

\section{Statistical analysis}

We first examined the correlations among weather indicators and pollutants with Spearman's correlation test. Then, we applied a Poisson generalized linear regression combined with distributed lag non-linear model (DLNM) to examine the non-linear and lagged effects of ambient temperature on outpatient admission for OA/RA, after controlling for long-term trend and seasonality, day of week (DOW), public holidays (Holiday), humidity, wind velocity, $\mathrm{PM}_{2.5}, \mathrm{SO}_{2}, \mathrm{NO}_{2}$ and $\mathrm{O}_{3}$. The core model is expressed as follows:

\section{$Y_{t} \sim \operatorname{Poisson}\left(\mu_{t}\right)$}

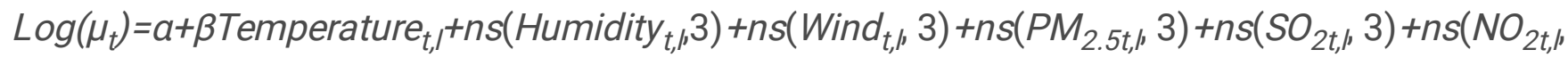
$3)+n s\left(O_{3 t, l} 3\right)+n s\left(\right.$ Time $\left._{t} 8\right)+\eta D O W_{t}+$ Holiday $_{t}$

Where $Y_{t}$ is the number of OA/RA admission on day $t$, a represents the intercept; Temperature $_{t, 1}$ Humidity $_{t, r}$ and Wind $_{t, l}$ are the cross-basis matrix produced by DLNM, $\beta$ is vector of coefficients for Temperature $_{t, l}$ and $/$ is the lag days; $n s()$ denotes a natural cubic spline; three degrees of freedom ( $d f s$ ) with lags 0-7 was used to adjust for humidity, wind velocity, $\mathrm{PM}_{2.5}, \mathrm{SO}_{2}, \mathrm{NO}_{2}$ and $\mathrm{O}_{3} ; 8$ dfs per year for time was used to control for long-term trend and seasonality; DOW and Holiday were controlled for in the model as a categorical variable, respectively.

On the basis of the lowest Akaike Information Criterion (AIC), we selected the maximum lag of four days to capture any single and cumulative effects of temperature. Because the plot of overall exposureresponse did not find the relationship between temperature and OA admission (Fig. 1), we only quantified the relative risks (RRs) of temperature change on RA admission by single day lags at low temperature (25th percentile, P25) compared to the reference temperature (50th percentile, P50). Furthermore, we examined the specific cumulative effects of temperature decrease on RA admission by gender (male and female) and age ( $0-17$ years, $18-40$ years, $41-65$ years and $\geq 66$ years).

To test the robustness of our results, sensitivity analyses were performed by varying $d f$ for time (7-9 $d f s /$ year), humidity (3-5 dfs) and wind velocity (3-5 dfs), respectively. Data manipulation and analyses were conducted using R software (version 3.1.1), with the "dlnm" package to fit the DLNM [14].

\section{Results}

\section{Descriptive statistics}

In total, 24838 OA cases and 43935 RA cases were reported over the study period. For OA admission, females and patients aged $41-65$ years accounted for $70.6 \%$ and $59.3 \%$, respectively. Of RA admission, 
there were more female cases $(36227,82.5 \%)$ and more cases aged $41-65$ years $(38564,87.8 \%)$. The value of daily mean temperature, rainfall and wind velocity were $16.8{ }^{\circ} \mathrm{C}, 75.5 \%$ and $1.9 \mathrm{~m} / \mathrm{s}$, respectively. The average concentration of $\mathrm{PM}_{2.5}, \mathrm{SO}_{2}, \mathrm{NO}_{2}$ and $\mathrm{O}_{3}$ during the study period were $64.6 \mu \mathrm{g} / \mathrm{m}^{3}$, $15.7 \mu \mathrm{g} / \mathrm{m}^{3}$ and $39.5 \mu \mathrm{g} / \mathrm{m}^{3}$ and $77.9 \mu \mathrm{g} / \mathrm{m}^{3}$, respectively. Detailed characteristics of the study population, weather indicators and air pollutants were presented in Tables 1 and 2.

Table 1

Characteristics of meteorological variables and air pollutants in Hefei, China, from 2014 to 2017.

\begin{tabular}{|c|c|c|c|c|c|c|}
\hline \multirow[t]{2}{*}{ Indicator } & \multirow[t]{2}{*}{ Mean \pm Sd } & \multicolumn{5}{|c|}{ Frequency distribution } \\
\hline & & $P(5)$ & $P(25)$ & $P(50)$ & $P(75)$ & $P(95)$ \\
\hline Mean temperature $\left({ }^{\circ} \mathrm{C}\right)$ & $16.8 \pm 9.0$ & 2.4 & 8.8 & 17.8 & 24.5 & 30.1 \\
\hline Relative humidity (\%) & $75.5 \pm 12.9$ & 52.0 & 67.0 & 76.0 & 85.0 & 95.0 \\
\hline Rainfall (mm) & $3.4 \pm 10.1$ & 0.0 & 0.0 & 0.0 & 0.9 & 19.8 \\
\hline Barometric pressure(hpa) & $1015 \pm 60.0$ & 1000.1 & 1005.5 & 1013.3 & 1021.1 & 1029.1 \\
\hline Wind velocity (m/s) & $1.9 \pm 0.7$ & 0.9 & 1.4 & 1.8 & 2.3 & 3.3 \\
\hline PM10 (ug/m³) & $95.0 \pm 49.1$ & 31.0 & 62.0 & 89.0 & 118.0 & 181.9 \\
\hline PM2.5 (ug/m³) & $64.6 \pm 39.9$ & 20.0 & 38.5 & 56.0 & 81.0 & 136.0 \\
\hline $\mathrm{SO} 2\left(\mathrm{ug} / \mathrm{m}^{3}\right)$ & $15.7 \pm 7.2$ & 8.0 & 10.0 & 14.0 & 19.0 & 29.0 \\
\hline NO2 (ug/m³) & $39.5 \pm 18.8$ & 17.1 & 27.0 & 35.0 & 48.0 & 77.0 \\
\hline $\mathrm{CO}\left(\mathrm{mg} / \mathrm{m}^{3}\right)$ & $1.0 \pm 0.3$ & 0.6 & 0.8 & 0.9 & 1.1 & 1.6 \\
\hline $03\left(\mathrm{ug} / \mathrm{m}^{3}\right)$ & $77.9 \pm 41.9$ & 25.0 & 46.0 & 68.0 & 103.0 & 160.0 \\
\hline
\end{tabular}


Table 2

Characteristics of daily cases for OA and RA in Hefei, China, during 2014-2017.

\begin{tabular}{|c|c|c|c|c|c|c|c|}
\hline \multirow[t]{2}{*}{ Group } & \multirow[t]{2}{*}{ Sum } & \multirow[t]{2}{*}{ Mean \pm SD } & \multicolumn{5}{|c|}{ Frequency distribution } \\
\hline & & & $P(5)$ & $P(25)$ & $P(50)$ & $P(75)$ & $\mathrm{P}(95)$ \\
\hline \multicolumn{8}{|c|}{ Osteoarthritis } \\
\hline Total & 24838 & $17.0 \pm 11.8$ & 0.0 & 7.0 & 16.0 & 25.0 & 38.0 \\
\hline Male & 7306 & $5.0 \pm 4.0$ & 0.0 & 2.0 & 4.0 & 7.0 & 12.0 \\
\hline Female & 17532 & $12.0 \pm 8.6$ & 0.0 & 5.0 & 11.0 & 18.0 & 27.0 \\
\hline$<17$ years & 430 & $0.3 \pm 0.6$ & 0.0 & 0.0 & 0.0 & 0.0 & 1.0 \\
\hline $18 \sim$ years & 4526 & $3.1 \pm 2.6$ & 0.0 & 1.0 & 3.0 & 5.0 & 8.0 \\
\hline $41 \sim$ years & 14732 & $10.1 \pm 7.4$ & 0.0 & 4.0 & 9.0 & 15.0 & 24.0 \\
\hline $66 \sim$ years & 5149 & $3.5 \pm 3.2$ & 0.0 & 1.0 & 3.0 & 5.0 & 10.0 \\
\hline \multicolumn{8}{|c|}{ Rheumatoid arthritis } \\
\hline Total & 43935 & $30.1 \pm 20.1$ & 0.0 & 7.0 & 34.0 & 46.0 & 58.0 \\
\hline Male & 7708 & $5.28 \pm 4.1$ & 0.0 & 2.0 & 5.0 & 8.0 & 13.0 \\
\hline Female & 36227 & $24.8 \pm 16.8$ & 0.0 & 6.0 & 28.0 & 39.0 & 49.0 \\
\hline$<17$ years & 199 & $0.14 \pm 0.4$ & 0.0 & 0.0 & 0.0 & 0.0 & 1.0 \\
\hline $18 \sim$ years & 7297 & $5.0 \pm 3.9$ & 0.0 & 1.0 & 5.0 & 8.0 & 12.0 \\
\hline $41 \sim$ years & 38564 & $19.6 \pm 13.5$ & 0.0 & 1.0 & 5.0 & 8.0 & 12.0 \\
\hline $66 \sim$ years & 7873 & $5.39 \pm 4.3$ & 0.0 & 1.0 & 5.0 & 9.0 & 13.0 \\
\hline
\end{tabular}

\section{Pairwise correlation between humidex and weather variables}

Spearman's correlation coefficients between weather variables and air pollutants in Hefei were shown in Table 3. It showed that temperature and relative humidity $\left(r_{s}=0.108\right)$, rainfall $\left(r_{s}=0.027\right)$, wind velocity $\left(r_{s}=0.060\right)$ were low. Meanwhile, prior studies reported that humidity increase can add the risk of arthritis admission $[8,19]$. Thus, humidity and wind velocity were controlled for as confounders in the regression model. Similarly, $\mathrm{PM}_{2.5}, \mathrm{SO}_{2}, \mathrm{NO}_{2}$ and $\mathrm{O}_{3}$ were included in the regression model. 


\begin{tabular}{|c|c|c|c|c|c|c|c|c|c|c|c|}
\hline Indicator & Temperature & Humidity & Rainfall & Pressure & Wind velocity & $\mathrm{PM}_{2.5}$ & $\mathrm{PM}_{10}$ & $\mathrm{SO}_{2}$ & $\mathrm{CO}$ & $\mathrm{NO}_{2}$ & $\mathrm{O}_{3}$ \\
\hline Temperature & 1.000 & 0.108 & 0.027 & -0.906 & 0.060 & -0.390 & -0.183 & $3-0.550$ & -0.308 & $3-0.264$ & $=0.553$ \\
\hline Humidity & & 1.000 & 0.659 & -0.237 & -0.065 & -0.188 & -0.419 & $9-0.405$ & 0.028 & -0.284 & $=-0.292$ \\
\hline Rainfall & & & 1.000 & -0.172 & 0.175 & -0.329 & -0.487 & -0.318 & -0.175 & -0.276 & -0.225 \\
\hline Pressure & & & & 1.000 & -0.084 & 0.360 & 0.211 & 0.524 & 0.267 & 0.306 & -0.461 \\
\hline Wind velocity & & & & & 1.000 & -0.292 & -0.304 & -0.128 & -0.399 & -0.401 & 0.005 \\
\hline $\mathrm{PM}_{2.5}$ & & & & & & 1.000 & 0.845 & 0.530 & 0.788 & 0.323 & -0.207 \\
\hline $\mathrm{PM}_{10}$ & & & & & & & 1.000 & 0.585 & 0.682 & 0.435 & 0.012 \\
\hline $\mathrm{SO}_{2}$ & & & & & & & & 1.000 & 0.511 & 0.235 & -0.322 \\
\hline $\mathrm{CO}$ & & & & & & & & & 1.000 & 0.453 & -0.213 \\
\hline $\mathrm{NO}_{2}$ & & & & & & & & & & 1.000 & 0.228 \\
\hline $\mathrm{O}_{3}$ & & & & & & & & & & & 1.000 \\
\hline
\end{tabular}

\section{Relationship between temperature change and admission for $\mathrm{OA}$ and $\mathrm{RA}$}

Fig. 1 showed the exposure-response relationship between temperature change and outpatient admission for OA and RA. It suggests that the temperature decrease was statistically associated with RA admission. In contrast, no significant association between temperature change and OA was observed. Hence, our study primary focuses on the results of the low temperature (P25) to explore the impact of temperature decrease on the risk of RA admission.

Table 4 presents the effects of temperature decrease on RA admission over different lag days, suggesting that temperature decrease was significantly associated with increased risk of RA admission. Significant effects of temperature decrease appeared immediately and lasted about two days, and its effect was the greatest at current day. Compared to the temperature $17.8^{\circ} \mathrm{C}$, a $9^{\circ} \mathrm{C}$ decrease in temperature was significantly associated with a $6.3 \%(1.063,95 \% \mathrm{Cl}: 1.010-1.118)$ increase of RA admission. We also observed that females and patients aged 41-65 years were more vulnerable to effect of temperature decrease. 


\begin{tabular}{|c|c|c|c|c|c|}
\hline Group & $\operatorname{Lag} 0$ & $\operatorname{Lag} 1$ & $\operatorname{Lag} 2$ & Lag 3 & $\operatorname{Lag} 4$ \\
\hline Total & $1.063(1.010-1.118)^{*}$ & $1.041(1.017-1.065)^{*}$ & $1.017(0.980-1.056)$ & $0.990(0.967-1.014)$ & $0.962(0.916-1.010)$ \\
\hline Male & $0.953(0.845-1.076)$ & $1.018(0.962-1.076)$ & $1.056(0.965-1.155)$ & $1.045(0.986-1.108)$ & $1.006(0.894-1.131)$ \\
\hline Female & $1.087(1.028-1.149)^{*}$ & $1.046(1.019-1.073)^{*}$ & $1.009(0.968-1.052)$ & $0.979(0.953-1.006)$ & $0.953(0.903-1.006)$ \\
\hline $0-17$ years & $0.865(0.394-1.898)$ & $0.918(0.638-1.320)$ & $0.944(0.534-1.669)$ & $0.922(0.634-1.339)$ & $0.872(0.404-1.881)$ \\
\hline $18-40$ years & $1.010(0.893-1.143)$ & $1.007(0.951-1.067)$ & $1.003(0.914-1.101)$ & $0.998(0.940-1.059)$ & $0.992(0.879-1.120)$ \\
\hline 41-65 years & $1.068(1.004-1.137)^{*}$ & $1.058(1.028-1.089) *$ & $1.036(0.989-1.085)$ & $0.997(0.967-1.027)$ & $0.949(0.893-1.008)$ \\
\hline$\geq 66$ years & $1.099(0.975-1.238)$ & $1.014(0.960-1.071)$ & $0.963(0.881-1.052)$ & $0.961(0.907-1.018)$ & $0.988(0.880-1.109)$ \\
\hline
\end{tabular}

* indicates statistical significance $(P<0.05)$

The cumulative effects of temperature decrease on RA admission stratified by gender and age were presented in Fig. 2. It also indicated that temperature decrease was more likely to affect RA admission among females and people aged 41-65 years, with the significant multi-day RR occurring at lag0-0 and continuing to lag0-3 days. Additionally, the multi-day metrics of low temperature exposure indicated a larger and prolonged effects on RA admission than single-days exposure.

\section{Sensitivity analyses}

To investigate whether the results were sensitive to the specification of parameters in the model, we changed $d f$ (7-9 per year) for time to control for the long-term trend and seasonality, and found the estimated effects of temperature did not change substantially (Supplementary Fig. S1). Moreover, we got similar results when changing $d f(3-5)$ for humidity and wind velocity (Supplementary Figs. S2 and S3).

\section{Discussion}

The influence of temperature on OA/RA pain is controversial and several published studies have not demonstrated a definite relationship between temperature change and OA/RA admission. This is the first time-series study so far to quantify the associations between temperature change and OA/RA admission with a large number of patients. Our results indicate that temperature decrease has acute and delayed adverse effect on RA admission. However, non-significant association between temperature and OA admission was observed. With regard to patients with RA, stratified analyses also provide evidence that females and patients aged 41-65 years might be more vulnerable to sudden temperature decrease than males and patients aged $0-40, \geqq 66$ years, respectively.

Our findings for OA might seem puzzling to some readers because it is well known that temperature can affect pain in patients with $O A[4,10,16]$. It may be related to cognitive misattribution. If a patient believes that rain causes pain, he or she will pay much attention to rainy days with much pain [13]. Meanwhile, many studies have been conducted in an attempt to establish the relationship between 
temperature change and OA $[6,16]$, but many of these studies with methodological limitations that may have affect their validity to some extent. For instance, the study by Strusberg in the field were based on the correlation analysis [4], and this method has various shortcomings (e.g. not adjusted for confounder and not provide the value of relative risk). Although several studies have attempted to use the regression model to explore the relationship between temperature and OA $[6,17]$, the delayed effects of ambient temperature on OA have not been investigated. Our findings are based on the results of a time-series study and has a number of strengths compared to past research.

The traditional belief of "Cold and wet is bad, warm and dry is good for RA patients" seems to be true [18]. This study found that temperature decrease could increase risk of RA admission, which is consistent with several previous studies $[3-5,19]$. The underling mechanism as to why temperature decrease could affect $\mathrm{OA}$ admission is not clear enough. Abasolo et al. proposed a hypothesis that cold can trigger some diseases such as crioglobulinemia or Raynaud phenomenon, both closely related to rheumatic diseases [3]. It may be possible that muscles also play a role in relation to flares or pain in RA patients and cold weather, due to coldness stiffens muscles around the joints that can worsen the arthritis symptoms. Another explanation is involvement of autonomic nerves to regulate threshold of pain. An animal study by Sato group found that both decreased temperature and air pressure led to worsening of joint pain in arthritic rats [20]. This group also reported low temperature exposure augments pain in animal model were mainly mediated by sympathetic nerve [21]. Nevertheless, further study focus on this complex area are still required.

Understanding the characteristics of susceptible population is important for policy makers to develop targeted intervention [22]. A limited number of previous studies have reported that individual characteristics such as age might modify the risk of weather factors on RA disease [3]. In this study, subgroup analysis by gender found that female patients were more sensitive to temperature decrease than male patients, which may be in part owing to differential body composition [23]. The age stratified analysis indicated that the association between temperature decrease and RA onset was significantly observed in patients aged 41-65 years, and this effect was not found in other age groups. This may be because of the fact that age itself is a risk factor for disability, thus elderly could have in general more difficulty to go to the hospital in time by themselves. Meanwhile, rheumatic pain is usually considered to be a natural part of the aging process. In order not to interfere with their study and work, young people may take other ways rather than going to the hospital to control their RA symptoms [3].

There were two major strengths in this study. To our knowledge, this is the first research to quantify both lagged and non-linear relationship between temperature and RA. Additionally, we collected four years data, controlled for air pollutants and explored the possible modification of confounders (e.g., gender and age) to examine the association between temperature change and RA admission. Several limitations of our study should also be noted. Firstly, the data were collected from one city, restricting our findings to be generalized to other regions of distinct weather pattern. Secondly, consistent with previous ecological studies, exposure misclassification should not be ignored because population exposure was used to represent personal exposure and air-conditioning was usually used in cold seasons. 


\section{Conclusions}

Temperature decrease was significantly associated with an increased risk of RA admission. Females and patients aged 41-65 years were more sensitive to temperature decrease than males and other age groups, respectively. As climate change progresses, temperature change will be more frequent, and patients may be at greater risk of RA onset associated with temperature decrease. Our findings highlighted that public health sector, medical staff and carers of RA patients should pay attention to cold weather when controlling and preventing RA onset.

\section{Additional Files}

Additional file 1: Supplementary materials.doc (doc 659kb)

Fig. S1 The overall effects of temperature change on OA/RA admission when changing the $d f(7-9$ $d f /$ year) for time.

Fig. S2 The overall effects of temperature change on OA/RA admission when varying the $d f(3-5)$ for relative humidity.

Fig. S3 The overall effects of temperature change on OA/RA admission when varying the df (3-5) for wind velocity.

\section{Abbreviations}

AIC: Akaike Information Criterion; CO: carbon monoxide; $d f s$ : degrees of freedom; DLNM: distributed lag nonlinear model; DOW: day of week; GBD: Global Burden of Disease; ICD: International Classification of Disease; $\mathrm{NO}_{2}$ : nitrogen dioxide; $\mathrm{OA}$ : osteoarthritis; $\mathrm{O}_{3}$ : ozone; $\mathrm{PM}_{10}$ : particulate matter of less than $10 \mu \mathrm{m}$; $\mathrm{PM}_{2.5}$ : particulate matter of less than $2.5 \mu \mathrm{m}$; RA: rheumatoid arthritis; RR: relative risk; $\mathrm{SO}_{2}$ : sulfur dioxide; YLD: years lived with disability.

\section{Declarations}

\section{Acknowledgements}

We would like to acknowledge and thank all of the participants in this study.

\section{Funding}

No external funding was required for this work.

\section{Availability of data and materials}

The data used in this study are available from the corresponding author on reasonable request. 


\section{Authors' contributions}

Desheng Zhao and Hong Su conceived and designed the study. Hao Wang, Yanwu Zhang and Fengjuan Liang collected and arranged the data. Desheng Zhao conducted data analysis. Desheng Zhao and Shiyuan Fang drafted the manuscript. Jian Cheng, Xu Wang and Hong Su revised the manuscript.

\section{Ethics approval and consent to participate}

Data collection was agreed by the Ethics Committee of Anhui Provincial Hospital.

\section{Consent for publication}

Not applicable.

\section{Competing interests}

The authors declare they have no competing financial interests.

\section{References}

1. Nagase H, Murphy G. Metalloproteinases in Cartilage Matrix Breakdown: The Roles in Rheumatoid Arthritis and Osteoarthritis. In: Brix K., Stöcker W. (eds) Proteases: Structure and Function. Springer, Vienna; 2013.

2. GBD 2017 Disease and Injury Incidence and Prevalence Collaborators. Global, regional, and national incidence, prevalence, and years lived with disability for 354 diseases and injuries for 195 countries and territories, 1990-2017: a systematic analysis for the Global Burden of Disease Study 2017. Lancet. 2018;392(10159): 1789-1858.

3. Abasolo L, Tobías A, Leon L, Carmona L, Fernandez-Rueda JL, Rodriguez AB, Fernandez-Gutierrez B, Jover JA. Weather conditions may worsen symptoms in rheumatoid arthritis patients: the possible effect of temperature. Reumatol Clin. 2013; 9(4):226-8.

4. Strusberg I, Mendelberg RC, Serra HA, Strusberg AM. Influence of weather conditions on rheumatic pain. J Rheumatol. 2002;29(2):335-8.

5. Tsai WS, Yang YH, Wang LC, Chiang BL. Abrupt temperature change triggers arthralgia in patients with juvenile rheumatoid arthritis. J Microbiol Immunol Infect. 2006;39(6):465-70.

6. Peultier L, Lion A, Chary-Valckenaere I, Loeuille D, Zhang Z, Rat AC, Gueguen R, Paysant J, Perrin PP. Influence of meteorological elements on balance control and pain in patients with symptomatic knee osteoarthritis. Int J Biometeorol. 2017;61(5): 903-910.

7. Hill DF. Climate and arthritis. In: Hollander JL, McCarty DC, editors. Arthritis and allied conditions: A textbook of rheumatology. Philadelphia: Lea \& Febiger. 1972; 256-63.

8. Savage EM, McCormick D, McDonald S, Moore O, Stevenson M, Cairns AP. Does rheumatoid arthritis disease activity correlate with weather conditions? Rheumatol Int. 2015;35(5):887-90. 
9. Sibley JT. Weather and arthritis symptoms. J Rheumatol. 1985;12(4):707-10.

10. Vergés J, Montell E, Tomàs E, Cumelles G, Castañeda G, Marti N, Möller I. Weather conditions can influence rheumatic diseases. Proc West Pharmacol Soc. 2004; 47:134-6.

11. Ferreira ML, Zhang Y, Metcalf B, Makovey J, Bennell KL, March L, Hunter DJ. The influence of weather on the risk of pain exacerbation in patients with knee osteoarthritis - a case-crossover study. Osteoarthritis Cartilage. 2016;24(12):2042- 2047.

12. Terao $C$, Hashimoto M, Furu M, Nakabo S, Ohmura K, Nakashima R, Imura Y, Yukawa N, Yoshifuji H, Matsuda F, Ito H, Fujii T, Mimori T. Inverse association between air pressure and rheumatoid arthritis synovitis. PLoS One. 2014;9(1):e85376.

13. Smedslund G, Hagen KB. Does rain really cause pain? A systematic review of the associations between weather factors and severity of pain in people with rheumatoid arthritis. Eur J Pain. 2011;15(1):5-10.

14. Gasparrini A, Armstrong B, Kenward MG. Distributed lag non-linear models. Stat Med. 2010;29:222434.

15. Zhao D, Zhang X, Xie M, Cheng J, Zhang H, Wang S, Li K, Yang H, Wen L, Wang X, Su H. Is greater temperature change within a day associated with increased emergency admissions for schizophrenia? Sci Total Environ. 2016;566-567:1545-155.

16. McAlindon T, Formica M, Schmid CH, Fletcher J. Changes in barometric pressure and ambient temperature influence osteoarthritis pain. Am J Med. 2007;120 (5):429-34.

17. Timmermans EJ, Schaap LA, Herbolsheimer F, Dennison EM, Maggi S, Pedersen NL, Castell MV, Denkinger MD, Edwards MH, Limongi F, Sánchez-Martínez M, Siviero P, Queipo R, Peter R, van der Pas S, Deeg DJ; EPOSA Research Group. The Influence of Weather Conditions on Joint Pain in Older People with Osteoarthritis: Results from the European Project on OSteoArthritis. J Rheumatol. 2015;42(10):1885-92.

18. Patberg WR, Rasker JJ. Weather effects in rheumatoid arthritis: from controversy to consensus. A review. J Rheumatol. 2004;31(7):1327-34.

19. Aikman H. The association between arthritis and the weather. Int J Biometeorol. 1997;40(4):192-9.

20. Sato J, Aoyama M, Yamazaki M, Okumura S, Takahashi K, Funakubo M, Mizumura K. Artificially produced meteorological changes aggravate pain in adjuvant -induced arthritic rats. Neurosci Lett. 2004;354(1):46-9.

21. Sato J, Morimae H, Takanari K, Seino Y, Okada T, Suzuki M, Mizumura K. Effects of lowering ambient temperature on pain-related behaviors in a rat model of neuropathic pain. Exp Brain Res. 2000;133(4):442-9.

22. McMichael AJ. Globalization, climate change, and human health. N Engl J Med. 2013;369(1):96.

23. Frascarolo P, Schutz Y, Jequier E. Decreased thermal conductance during the luteal phase of the menstrual cycle in women. J Appl Physiol. 1990;69:2029-33. 
Figures

Osteoarthritis

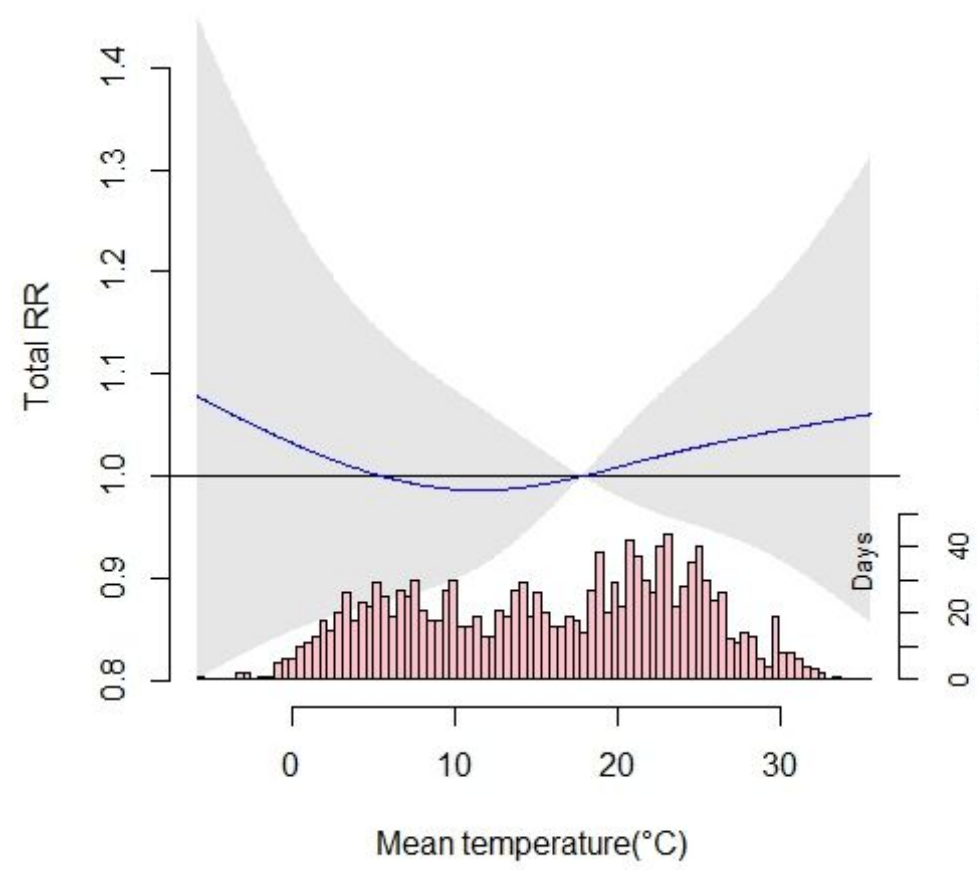

\section{Rheumatoid arthritis}

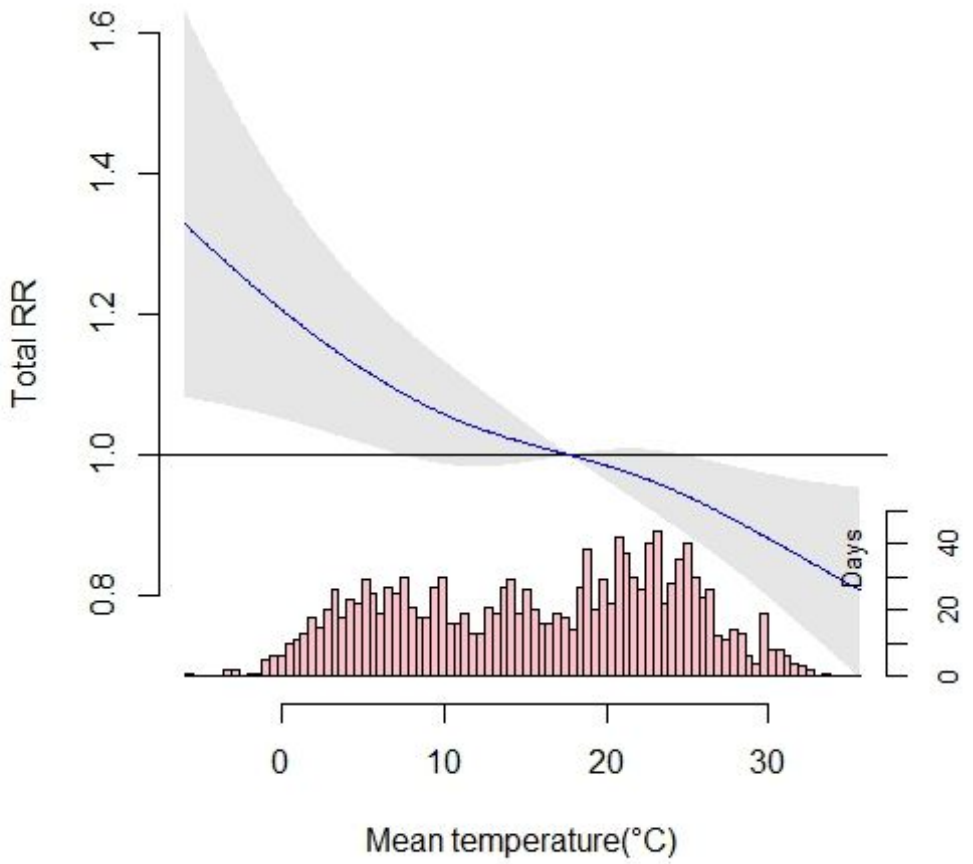

\section{Figure 1}

Overall effects of exposure-response associations between temperature change and outpatient admission for OA and RA. 

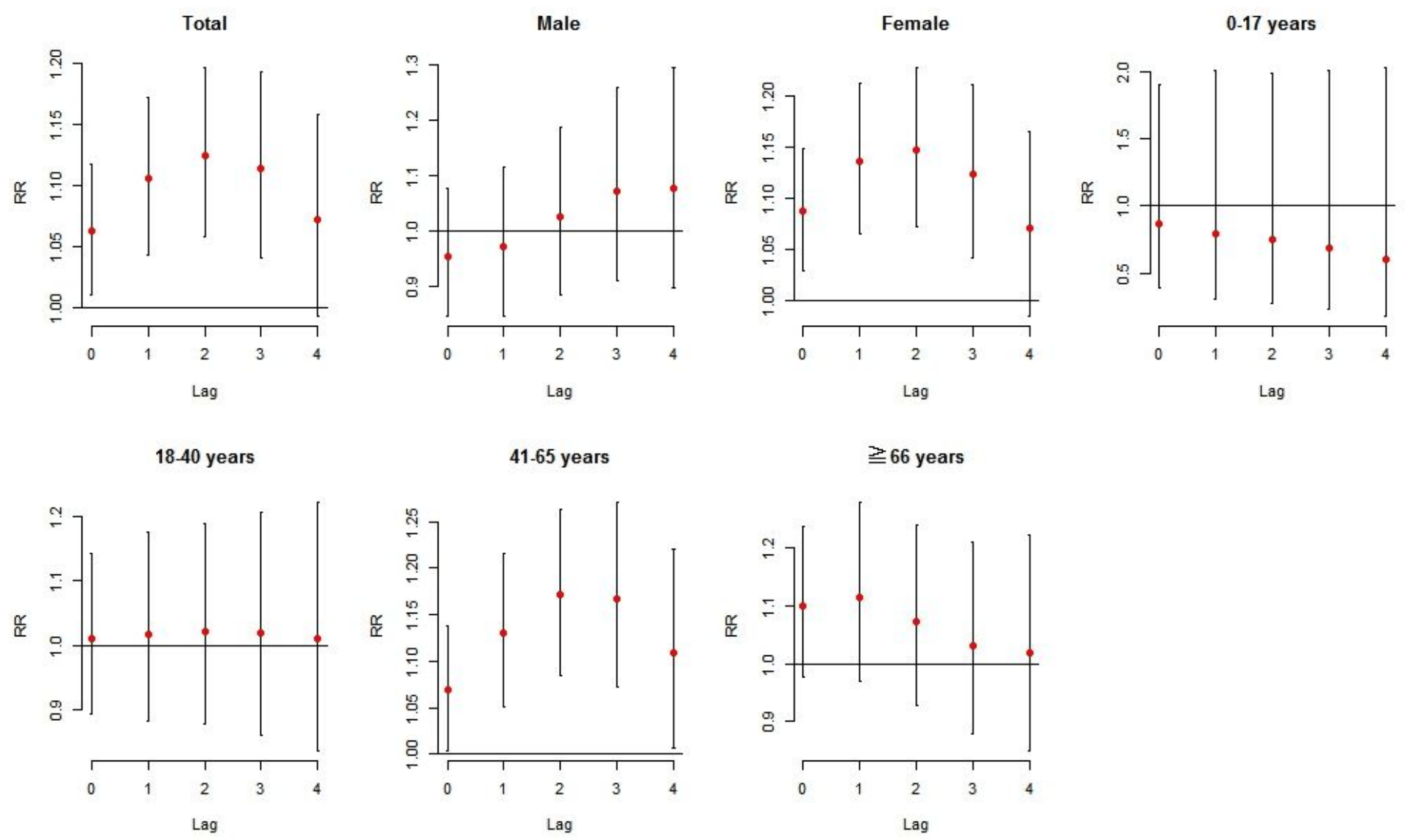

\section{Figure 2}

The specific cumulative effects of temperature decrease on RA admission by gender, age and classification of arthritis at different lag days, with P25 of temperature versus P50.

\section{Supplementary Files}

This is a list of supplementary files associated with this preprint. Click to download.

- Supplementarymaterials.doc 